\title{
Pulmonary Eosinophilic Granulomatosis with Polyangiitis Has IgG4 Plasma Cells and Immunoregulatory Features
}

Zachary M. Dong, ${ }^{*}$ Edwin Lin, ${ }^{* \dagger}$ Michael E. Wechsler, ${ }^{\ddagger}$ Peter F. Weller, ${ }^{\S}$ Amy D. Klion, ${ }^{\oplus}$ Bruce S. Bochner,, Don A. Delker, ${ }^{*}$ Mark W. Hazel, ${ }^{*}$ Keke Fairfax, ${ }^{*}$ Paneez Khoury, ${ }^{\mathbb{\pi}}$ Praveen Akuthota, ${ }^{* *}$ Peter A. Merkel, ${ }^{\dagger \dagger}$ Anne-Marie Dyer, ${ }^{\ddagger}$ Carol Langford, ${ }^{\S}$ Ulrich Specks, ${ }^{\top \uparrow}$ Gerald J. Gleich, ${ }^{*}$ Vernon M. Chinchilli, ${ }^{\dagger \dagger}$ Benjamin Raby, ${ }^{\ddagger \ddagger\|\|}$ Mark Yandell, ${ }^{* \dagger}$ and Frederic Clayton*

From the University of Utah, * Salt Lake City, Utah; the Department of Human Genetics, ${ }^{\dagger}$ USTAR Center for Genetic Discovery, Salt Lake City, Utah; the National Jewish Health, ${ }^{\ddagger}$ Denver, Colorado; the Beth Israel Deaconess Medical Center ${ }^{\S}$ and the Brigham and Woman's Hospital, ${ }^{\|\|}$Harvard Medical School, Boston, Massachusetts; the Laboratory of Parasitic Diseases, "National Institute of Allergy and Infectious Diseases, NIH, Bethesda, Maryland; the Northwestern University Feinberg School of Medicine, "Chicago, Illinois; the University of California, San Diego, ** San Diego, California; the University of Pennsylvania ${ }^{\dagger \dagger}$ Philadelphia, Pennsylvania; the Penn State College of Medicine, ${ }^{\ddagger \ddagger}$ Hershey, Pennsylvania; the Cleveland Clinic, ${ }^{\S \S}$ Cleveland, Ohio; and the Mayo Clinic, ${ }^{\text {ศा }}$ Rochester, Minnesota

Accepted for publication March 4, 2020.

Address correspondence to Frederic Clayton, M.D., Huntsman Cancer Institute, 2000 Circle of Hope, Room 3100, Salt Lake City, UT 84112. Email: fred.clayton@ path.utah. edu.
The immunologic mechanisms promoting eosinophilic granulomatosis with polyangiitis (EGPA) are unclear. To characterize the mechanisms underlying pulmonary EGPA, we examined and compared EGPA paraffin-embedded lung biopsies with normal lung biopsies, using immunostaining, RNA sequencing, and RT-PCR. The results revealed novel type 2 as well as immuneregulatory features. These features included basophils and increased mast cell contents; increased immunostaining for tumor necrosis factor ligand superfamily member 14; sparse mast cell degranulation; numerous forkhead box protein P3 (FoxP3) + regulatory T cells and IgG4 plasma cells; and abundant arachidonate 15-lipoxygenase and 25-hydroxyvitamin D-1 $\alpha$ hydroxylase, mitochondrial. Significantly decreased 15-hydroxyprostaglandin dehydrogenase $\left[\operatorname{NAD}\left({ }^{+}\right)\right]$, which degrades eicosanoids, was observed in EGPA samples. In addition, there was significantly increased mRNA for chemokine (C-C motif) ligands 18 and 13 and major collagen genes, IgG4-rich immune complexes coating alveolar macrophages, and increased immunostaining for phosphorylated mothers against decapentaplegic homolog 2/SMAD2, suggesting transforming growth factor- $\beta$ activation. These findings suggest a novel self-promoting mechanism of activation of alveolar macrophages by arachidonate 15-lipoxygenase-derived eicosanoids to express chemokines that recruit a combined type 2/immunoregulatory immune response, which produces these eicosanoids. These results suggest that the pulmonary EGPA immune response resembles the immune response to a
Supported by NIH grant NIAID-U-01 AI097073 (M.E.W.); the Division of Intramural Research, National Institute of Allergy and Infectious Diseases, NIH; and National Cancer Institute award number P30CA042014.

The content is solely the responsibility of the authors and does not necessarily represent the official views of the National Cancer Institute or the NIH.

Z.M.D. and E.L. contributed equally to this work.

Disclosures: P.A.M. consults for AbbVie, AstraZeneca, Biogen, Boeringher-Ingelheim, Bristol-Myers Squibb, Celgene, ChemoCentryx, CSL Behring, Genentech/Roche, Genzyme/Sanofi, GlaxoSmithKline, InflaRx, Insmed, Jannsen, Kiniksa, and Sparrow; research support from AstraZeneca, Boeringher-Ingelheim, Bristol-Myers Squibb, Celgene, ChemoCentryx, Genentech/Roche, Genzyme/Sanofi, GlaxoSmithKline,
InflaRx, Kypha, and Terumo BCT; B.S.B. has ongoing scientific advisory board arrangements with Allakos, Inc., and owns stock in Allakos, Inc., is a co-inventor on existing Siglec-8-related patents and thus may be entitled to a share of royalties received by Johns Hopkins University on the potential sales of such products, is also a cofounder of Allakos, Inc., which makes him subject to certain restrictions under university policy (the terms of this arrangement are being managed by John Hopkins University and Northwestern University in accordance with their conflict of interest policies); P.A. has advisory board, consulting, and clinical trial site relationships with GSK and AstraZeneca; U.S. consults for AstraZeneca, ChemoCentryx, and Insmed, and has research support from AstraZeneca, Bristol-Myers Squibb, ChemoCentryx, Genentech/Roche, GlaxoSmithKline, and InflaRx. 
Eosinophilic granulomatosis with polyangiitis (EGPA) is a rare systemic disease characterized by eosinophilic asthma, sinus disease, pulmonary infiltrates, and vascular eosinophil infiltrates with vasculitis. Because lung biopsies are rarely done in EGPA and because there are no good EGPA animal models, the lung immunopathology of this rare disease has not been carefully studied.

Therapeutic trials, gene association studies, and flow cytometry of blood from EGPA patients all provide clues to its immune pathophysiology. Beneficial effects have been shown for treatments targeting eosinophils ${ }^{1}$ (mepolizumab, anti-IL-5), B cells ${ }^{2,3}$ (rituximab, anti-CD20), and antibodies ${ }^{4}$ (intravenous immunoglobulins and plasmapheresis). Leukotriene modifier therapy is linked to an increased risk for developing EGPA. ${ }^{5,6}$ Patients with active EGPA have high serum IgG4. ${ }^{7}$ IgG4 is IL-10 induced. ${ }^{8}$ EGPA is associated with specific human leukocyte antigen-DR variants ${ }^{9}$ and an ILIO promotor allele that increases IL-10 expression. ${ }^{10}$ These suggest mechanistic roles for eosinophils, B cells or antibodies, eicosanoids, T-helper cells, and IL-10.

Terrier et $\mathrm{al}^{11}$ had predicted the pathogenic role for eosinophils and T cells on the basis of a possible self-promoting pathway involving eosinophils, T cells, and IL-25. Tsurikisawa and Saito and colleagues ${ }^{12-17}$ showed that peripheral blood regulatory $\mathrm{T}$ cell (Treg) content is decreased in active EGPA patients relative to healthy controls and to patients with inactive EGPA, asthma, and chronic eosinophilic pneumonia. They concluded that Tregs prevent or suppress EGPA and that Treg content was reduced in active disease. However, evidence against this included the ILIO gene promoter association, ${ }^{10}$ that EGPA bronchoalveolar lavage specimens have increased $I L 10$ and FOXP3 RNA, ${ }^{18}$ and the presence of abundant serum IgG4, ${ }^{7}$ presumably IL-10 induced, ${ }^{8}$ in active EGPA. Alternatively, Tregs might not be lost, but instead recruited from blood into tissue during active disease. In this study, we characterize the immune infiltrates in EGPA using both RNA sequencing and immunostaining. We show a combined type 2 and immunoregulatory infiltrate with abundant Tregs, IgG4 plasma cells, basophils, and immune complexes, as well as chemokines needed to recruit and sustain this infiltrate.

\section{Materials and Methods}

\section{Criteria and Subjects}

Lung biopsies were obtained from six EGPA subjects meeting American College of Rheumatology criteria, ${ }^{19}$ with active disease at the time of biopsy. All available cases were used without regard for statistical power. All studies were institutional review board approved. Informed consent was obtained as required. Controls were histologically normal lung tissue removed in tumor resections.

\section{Histopathology and Immunostaining}

Routine hematoxylin and eosin sections and immunostains were examined in a blinded manner (F.C.). Immunostaining was done either manually or with a Ventana Benchmark Ultra (Santa Clara, CA) or Leica Bond (Richmond, IL) stainer. Manual immunoperoxidase staining was done with SignalStain reagents (Cell Signaling Technology, Danvers, MA). Manual immunofluorescence staining was done with goat anti-rabbit and goat anti-mouse antibodies conjugated with Alexa488, Alexa 647, or Cy3 (Jackson Immunoresearch, West Grove, PA) and DAPI counterstained. Primary antibodies are listed in Table 1.

An Olympus BX60 fluorescent microscope (Waltham, MA) was used (0.54-mm high-power field diameter). Confocal microscopy was done with a Nikon A1 confocal microscope (Melville, NY). Manual immunostains were done after pressure cooker EDTA-based antigen retrieval (Trilogy; Cell Marque, Rocklin, CA), and incubated in 3.5\% normal goat serum for 30 minutes. Antibody incubations were 9 to 12 hours at room temperature. Manual immunoperoxidase stains were done with SignalStain immunostaining kits from Cell Signaling Technology, using their methods. Automated immunostains were done on Ventana Benchmark Ultra or Leica Bond. Statistical significance was assessed by $U$-test (GraphPad Prism, version 8; GraphPad Software, San Diego, CA).

\section{RNA Extraction and RNA Sequencing}

RNA methods were as previously described. ${ }^{20}$ Total RNA was extracted from formalin-fixed, paraffin-embedded tissue (10 $\mu \mathrm{m}$ thick) using the High Pure FFPET RNA Isolation kit (Roche, Indianapolis, IN). DNA was removed from the RNA samples using the manufacturer's suggested DNase one-digestion step. RNA quantity was determined with a NanoDrop spectrophotometer (Thermo Fisher Scientific, Waltham, MA). RNA samples were prepared for RNA sequencing using the Illumina TruSeq Stranded Total RNA Sample Prep protocol (Illumina, San Diego, CA), which included removing ribosomal RNA. An Illumina HiSeq 2500 was used to sequence the PCR amplified libraries using 50-cycle single-read chemistry.

\section{Bioinformatics Analysis}

FASTQC version 0.11.6 (Babraham Institute, Cambridgeshire, UK) was used to perform quality control checks on raw sequence data. Quantification of Ensembl human cDNA 
(release 91) was performed using Kallisto and Taxonomer software. ${ }^{21}$ DESeq2 was used for differential expression analysis. Criteria for differentially expressed genes were as follows: a mean read count of at least 10 , a $\log 2$ fold change $>2$, and $P<0.05$ after correction for false discovery rate. The mean number of reads mapped to human genes per case were 4,668,600 among the RNA-sequencing cases and $7,124,500$ among controls. A total of 2309 genes were differentially expressed; 1493 genes were significantly upregulated and 816 genes were significantly down-regulated in EGPA relative to controls. RNA-sequencing data generated in this study are available on National Center for Biotechnology Information Gene Expression Omnibus (https://www.ncbi.nlm.nih.gov/geo; accession number GSE144302).

\section{RT-PCR}

Selected genes crucial to the proposed mechanism were also examined by real-time quantitative RT-PCR. Total RNA was reverse transcribed to cDNA using Applied Biosystems (Foster City, CA) High-Capacity RNA-to-cDNA kit. Relative mRNA levels for $I L 10, I L 13, C C L 18$, and the reference genes GLYRI and WDFY2 were measured using intronspanning TaqMan gene expression assays and TaqMan fast advanced master mix (Applied Biosystems). Reference genes were chosen on the basis of their moderate expression and lack of shift between sample categories by RNA sequencing. GLYRI was chosen as the reference gene for relative quantitation. Similar results were obtained using WDFY2 as the reference gene. Quantitative PCRs were performed in 384-well plates and run in triplicate in a Life Technologies (Carlsbad, CA) QuantiStudio 12K Flex RealTime PCR instrument. Fold change was determined by the $\Delta \Delta \mathrm{C}_{\mathrm{T}}$ method. Statistical significance was assessed by $t$-test in GraphPad Prism.

\section{Results}

\section{Study Population}

All six subjects had active EGPA at the time of lung biopsy and were previously diagnosed with asthma. Five biopsies were open lung; one was transbronchial. Two subjects were not on corticosteroid therapy at the time of biopsy, two were taking inhaled corticosteroids, and two were on oral prednisone. See Supplemental Table S1 for details.

For RNA sequencing, three cases (mean age, 36 years) and four controls (mean age, 34 years) were studied. All three EGPA RNA-sequencing subjects were female; two of four controls were male. One subject from each category (no corticosteroids, inhaled corticosteroids, and oral corticosteroids) was studied by RNA sequencing.

For RT-PCR, four EGPA cases (mean age, 33 years) and 10 controls (mean age, 32 years) were studied. All four EGPA cases and eight of 10 controls were female.
For histology and immunohistology, six EGPA cases (mean age, 36 years) and seven controls (mean age, 31 years) were studied. Two of six EGPA cases and two of seven controls were male. The transbronchial biopsy was only used for some stains; the block was exhausted.

\section{Histologic Findings}

All five open lung biopsies from EGPA patients had alveolar and interstitial infiltrates. The alveolar infiltrates were abundant in four cases, and were composed of many eosinophils with focal degranulation, numerous alveolar macrophages, and occasional giant cells, all focally embedded in fibrin (Figure 1, A and B, and Supplemental Figure S1). Both alveolar and, rarely, interstitial macrophages formed aggregates, some of which were cohesive enough to be considered granulomas.

Interstitial infiltrates were mostly pleural, septal, and around airways, and had lymphocytes, eosinophils, some macrophages, and plasma cells (Figure 1, A and C). Interstitial edema was minimal to absent. Three EGPA open lung biopsies had eosinophil-rich infiltrates in small artery and vein walls without fibrinoid necrosis (nonnecrotizing vasculitis) (Supplemental Figure S2). Sparse eosinophil and macrophage-rich areas of parenchymal necrosis were present in two open biopsies. Small areas with neutrophils were present in each case (Figure 1D). Trichrome stains (not shown) demonstrated only minimal, mostly subpleural fibrosis. The transbronchial biopsy, from a patient on oral corticosteroid therapy, had similar interstitial infiltrates, but lacked alveolar infiltrates. The open lung biopsy from a patient on oral corticosteroids had less alveolar infiltrate and fewer eosinophils than the other open biopsies; the interstitial findings were similar.

\section{Main Cell Populations and Phosphorylated SMAD2}

By immunostaining, many interstitial lymphocytes were $\mathrm{CD} 19^{+} \mathrm{B}$ cells or $\mathrm{CD} 4^{+} \mathrm{T}$ cells, with fewer $\mathrm{CD} 8^{+} \mathrm{T}$ cells (Figure 2, A-E). Most CD68 ${ }^{+}$macrophages were in alveolar aggregates/granulomas (Figure 2F). Many alveolar macrophages were $\mathrm{CD}^{+}$(Figure $2 \mathrm{C}$ ).

The five open lung biopsies from patients with EGPA had extensive nuclear plus cytoplasmic immunostaining in many cell types for phosphorylated mothers against decapentaplegic homolog 2 (phosphorylated SMAD2) (Figure 3A). The seven controls had sparse but definite phosphorylated SMAD2 nuclear staining, far less than in EGPA cases $(P=0.0025)$ (Figure $3 \mathrm{~B}$ and Supplemental Figure S3). Tissue basophils were seen in four of five EGPA open biopsies (Figure 3C). No basophils were seen in seven control lung biopsies $(P=0.0091)$ (Figure 3D and Supplemental Figure S3). Mast cells, stained by tryptase $\delta$ (mast cell tryptase), were abundant in the EGPA patient open lung biopsies (Figure 3E), more than the control lungs 
Table 1 Primary Antibodies Used

\begin{tabular}{|c|c|c|c|}
\hline Antibody specificity & Clone & Manufacturer & Stainer used \\
\hline ALOX15 & EPR22138 & Abcam, Cambridge, MA & Manual \\
\hline ALOX15 & $7 \mathrm{H} 6$ & Origene, Rockville, MD & Manual \\
\hline CD68 & KP-1 & Dako, Santa Clara, CA & Ventana, manual \\
\hline CD3 & LN10 & Biocare, Pacheco, CA & Leica, manual \\
\hline $\mathrm{CD} 3$ & SP7 & Abcam & Manual \\
\hline $\mathrm{CD} 4$ & 4B12 & Leica, Buffalo Grove, CA & Leica \\
\hline CYP27B1 & EPR20271 & Abcam & Manual \\
\hline FoxP3 & 236A/E7 & Abcam & Manual \\
\hline FoxP3 & D2W8E & $\begin{array}{l}\text { Cell Signaling Technology, } \\
\text { Beverly, MA }\end{array}$ & Manual \\
\hline 15-PGDH & EPR14332 & Abcam & Manual \\
\hline LIGHT (TNFSF14) & Rabbit polyclonal & Novus, Centennial, CO & Manual \\
\hline Phosphorylated SMAD2 & EPR2856 & Abcam & Manual \\
\hline Pro-MBP, for basophils & J175-7D4 & Gift from Hirohita Kita (Mayo Clinic, Rochester, MN) & Manual \\
\hline Rhodamine red $\mathrm{X}$ anti-human IgG & Goat polyclonal & Jackson Immunoresearch, West Grove, PA & Manual \\
\hline
\end{tabular}

CD68, macrosialin; CD4, T-cell surface glycoprotein CD4; CD19, B-lymphocyte antigen CD19; FoxP3, forkhead box protein P3; 15-PGDH, 15-hydroxyprostaglandin dehydrogenase $[\operatorname{NAD}(+)]$; LIGHT (TNFSF14), tumor necrosis factor ligand superfamily member 14; SMAD2, mothers against decapentaplegic homolog 2; Pro-MBP, bone marrow proteoglycan.

$(P=0.0025)$ (Figure $3 \mathrm{~F}$ and Supplemental Figure S3). Mast cell degranulation was sparse.

\section{RNA Sequencing and RT-PCR}

RNA sequencing was done on lung biopsy tissue of three patients with EGPA and four controls. Mean numbers of reads mapped to human genes per case were 4,668,600 among the RNA-sequencing cases and 7,124,500 among controls. Using stringent criteria, 2309 genes were differentially expressed; 1493 genes were significantly up-regulated and 816 genes were significantly down-regulated in EGPA relative to controls. Selected results are shown in Table 2 and in the volcano plot (Supplemental Figure S4).

Chemokine RNAs for CCL18 and CCL13 were markedly increased in EGPA, as was that for ALOX15 (arachidonate 15-lipoxygenase), which induces alveolar macrophages CCL18 and CCL13. HPGD RNA was decreased 24-fold in the EGPA cases.

Type 2-related RNAs for SIGLEC8, TNFSF 14, and IGHE were increased in EGPA. IL13, ILA, and IL5 had too few reads for RNA-sequencing evaluation, but RT-PCR indicated significantly increased IL13 expression in EGPA (see below). TNFSF14 (tumor necrosis factor ligand superfamily 14, protein is also called LIGHT, which has type 2 and immunoregulatory effects) was increased 17.5-fold in EGPA.

Immunoregulatory RNAs FOXP3, IGHG4, and CYP27B1 were all significantly more abundant in EGPA. IGHG4 was increased 1885-fold. RNA for the Treg-related gene $F O X P 3$ was increased eightfold in EGPA relative to controls. $C Y P 27 B 1 / 25$-hydroxyvitamin D-1 $\alpha$ hydroxylase, mitochondrial, hereafter abbreviated as VD3 1A hydroxylase, which synthesizes calcitriol, was increased 11-fold in EGPA relative to controls. CYP24A1 (which metabolizes calcitriol) was essentially unchanged in EGPA. IL10 RNA was increased eightfold, but had insufficient reads for reliable interpretation.

RNAs characteristic of B cells, macrophages, and Ig heavy chains were increased in EGPA, but IgG4 was the most increased isotype (increased 1885-fold; $P=1.7 \times$ $\left.10^{-15}\right)$. In addition to the increased $A L O X 15$, there was decreased HPGD RNA content.

Compared with controls, lung tissue in EGPA had significantly increased IL13 (20-fold; $P=0.0085)$ and CCL18 RNA (21-fold; $P=0.03$ ), but not IL10 (3.4-fold increase; $P=0.18)$.

\section{$\operatorname{IgG4}$}

IgG4 plasma cell infiltrates were extensive (Figures $2 \mathrm{G}$ and 4A). The five EGPA open lung biopsies had a median of 90 (range, 21 to 140 ) $\mathrm{IgG}^{+}$plasma cells per maximal highpower field, versus a median of 0 (range, 0 to 1 ) IgG4 plasma cells in seven control samples $(P=0.0013)$ (Supplemental Figure S3). By combined IgG and IgG4 immunofluorescence staining, most $\mathrm{IgG}^{+}$plasma cells were $\mathrm{IgG}^{+}$(Supplemental Figure S5). The IgG4 plasma cell infiltrates were often subpleural, peribronchial, or septal, and were exclusively in the interstitium rather than alveolar spaces. There was interstitial and intra-alveolar IgG4 


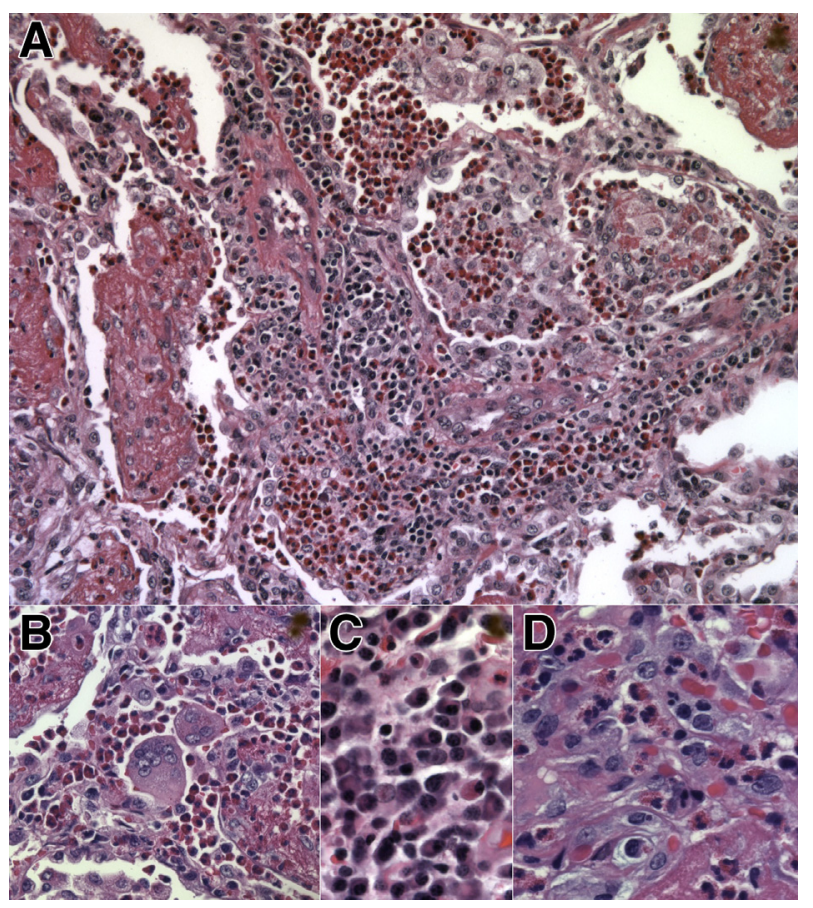

Figure 1 Eosinophilic granulomatosis with polyangiitis (EGPA) has distinctive alveolar and interstitial infiltrates. A: The alveolar infiltrate has abundant eosinophils, macrophages, and fibrin. The interstitium has abundant lymphocytes, eosinophils, and macrophages. B: Intra-alveolar giant cells are present but sparse. C: Focally, the interstitium has abundant plasma cells. D: In occasional fields of each EGPA open biopsy, neutrophils are also present. Original magnification: $\times 67($ A); $\times 83($ B $) ; \times 140$ (C); $\times 150$ (D).

staining, often coating alveolar macrophages and giant cells (Figure 4B). By confocal microscopy, the extracellular IgG and IgG4 was often granular, resembling immune complexes, focally coating $\mathrm{CD}^{+} 8^{+}$alveolar macrophages (Figure 4C). Both IgG4 antibodies stained similarly. The granular extracellular staining for IgG4 and for total IgG was generally similar (not shown).

\section{Regulatory T Cells}

Confirming the RNA-sequencing finding of increased FOXP3 RNAs, FoxP3 ${ }^{+}$cells, presumed Tregs, were abundant in EGPA lung tissue but rare in controls $(P=0.011 ; U$ test) (Figure 4D and Supplemental Figure S3). All FoxP3 ${ }^{+}$ cells were $\mathrm{CD}^{+}{ }^{+}$Supplemental Figure S6). Many FoxP3 ${ }^{+}$ cells were in subpleural or interstitial lymphoid aggregates; some were in alveolar macrophage infiltrates. Both FoxP3 antibodies stained similarly.

\section{Eicosanoid-Related Immunostains}

Eosinophils were the main site of arachidonate 15lipoxygenase immunostaining (Figures $2 \mathrm{H}$ and $5 \mathrm{~A}$ ). All eosinophils stained strongly for arachidonate 15lipoxygenase, as did some alveolar macrophages. Control lung cases had virtually no arachidonate 15-lipoxygenase staining, substantially less than in the EGPA cases $(P=0.0012)$ (Figure 5B and Supplemental Figure S3). Respiratory epithelial cell and pleural mesothelial arachidonate 15-lipoxygenase staining was found in both EGPA cases and controls (not shown). Both arachidonate 15lipoxygenase antibodies stained similarly.

In the EGPA open lung biopsies, immunostaining for 15-hydroxyprostaglandin dehydrogenase $\left[\mathrm{NAD}\left(^{+}\right)\right]$, referred to as 15-PGDH, in the EGPA open biopsies was minimal to negative in both alveolar macrophages and alveolar epithelium (Figure 5C), but confluently present in control case pneumocytes (Figure 5D). In the EGPA cases, a minority of lymphocytes and sparse intermediate sized cells had 15-PGDH staining. The 15-PGDH ${ }^{+}$intermediate-sized cells had abundant staining, whereas staining was far weaker in the positivestaining lymphocytes (Supplemental Figure S7). By RNA sequencing, HPGD expression was decreased 24-fold in the EGPA cases (see RNA Sequencing and $R T$-PCR above and Table 2).
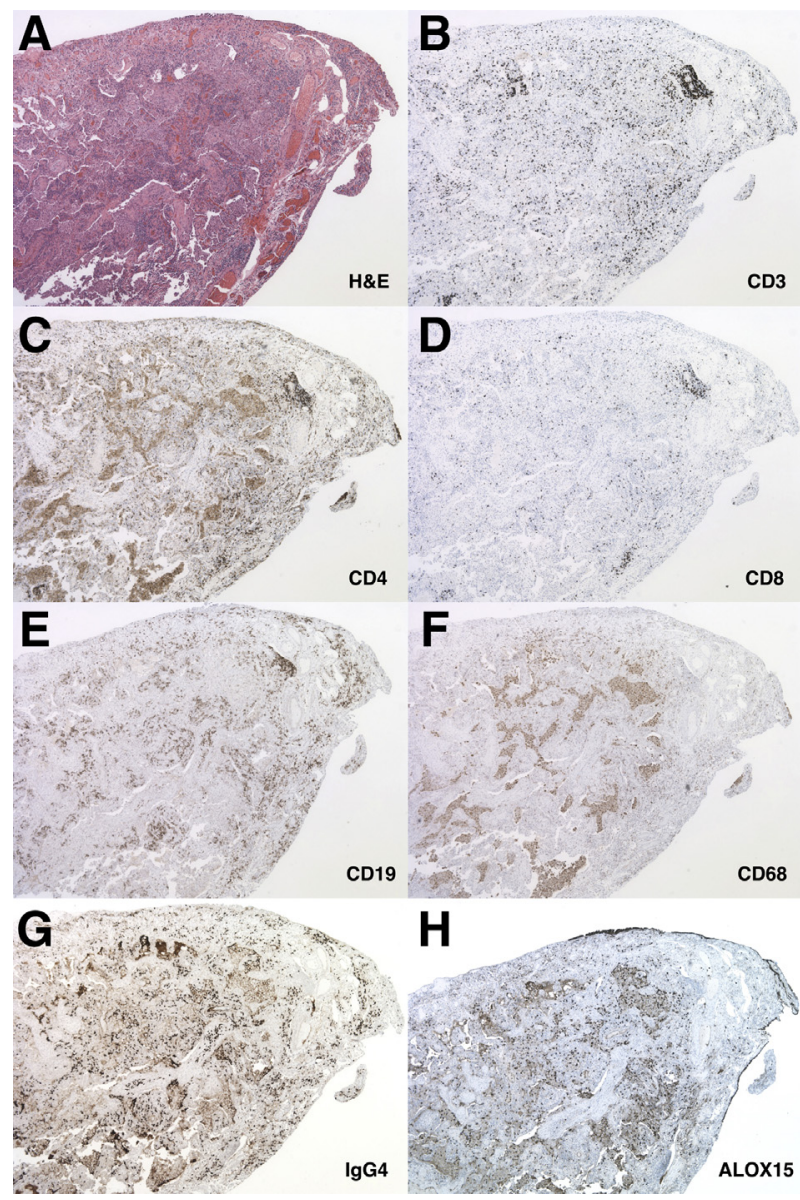

Figure 2 Sections of the same eosinophilic granulomatosis with polyangiitis (EGPA) lung tissue, showing staining for various antigens. A: Hematoxylin and eosin (H\&E) stain. B: CD3 (T cells). C: CD4 (T-helper cells and, more faintly, some macrophages). D: CD8 (cytotoxic T cells). E: CD19 (B cells). F: CD68 (macrophages). G: IgG4. H: Arachidonate 15lipoxygenase (eosinophils, mesothelium, and, more faintly, a minority of macrophages). Original magnification, $\times 12(\mathbf{A}-\mathbf{H})$. 


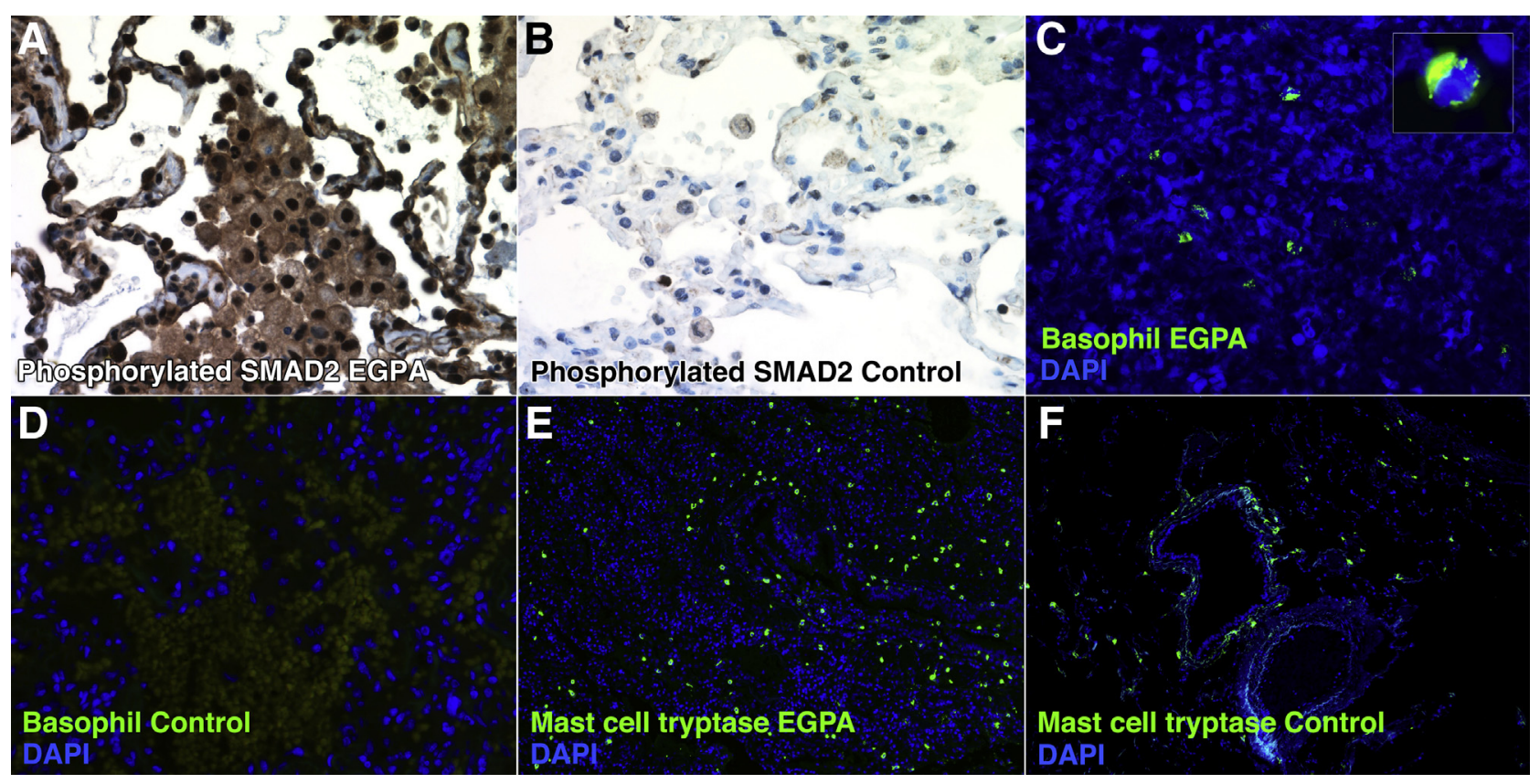

Figure 3 Increased phosphorylated SMAD2, increased numbers of basophils, and mast cells are present in eosinophilic granulomatosis with polyangiitis (EGPA) lung biopsies. A: Phosphorylated SMAD2 immunostains in EGPA, showing abundant alveolar macrophage and epithelial cell staining. B: Phosphorylated SMAD2 immunostain in a control, showing definite nuclear staining, but far less than in the EGPA biopsies. C: Basophil immunostain (green) in EGPA. Inset: A basophil at high magnification with coarse cytoplasmic basophil granules. D: Basophil immunostain in control lung, showing no basophils. E: EGPA lung mast cell tryptase immunostain (green), showing abundant mast cells. Mast cell degranulation was sparse (not shown). F: Control lung, showing fewer mast cells. Original magnification: $\times 150(\mathbf{A}-\mathbf{D}) ; \times 500$ (inset in $\mathbf{C}) ; \times 55(\mathbf{E}$ and $\mathbf{F})$.

\section{Other Immunoregulatory and Type 2-Related Immunostains}

VD3 1A hydroxylase ${ }^{+}$cells were increased in the EGPA open lung biopsies (Figure 6A) compared with the seven controls $(P=0.0025)$ (Figure 6B and Supplemental Figure S3). Alveolar macrophages had extensive granular cytoplasmic staining resembling mitochondria. Alveolar macrophages also stained for VD3 A1 hydrolase and pneumocytes, and other cells were extensively stained in the EGPA cases only. LIGHT immunostaining was present mainly in alveolar and interstitial macrophages. Macrophages were generally $\mathrm{LIGHT}^{+}$, and were substantially more abundant in the EGPA biopsies (Figure 6C) than in controls $(P=0.0025)$ (Figure 6D and Supplemental Figure S3).

\section{Discussion}

In summary, the data show that EGPA has both type 2 and immunoregulatory features. Type 2 features include infiltrates with eosinophils, basophils, and mast cells, and RNAs for IL13, TNFSF14, and SIGLEC8. Immunoregulatory features include the presence of Foxp $3^{+}$Tregs, IgG4 plasma cells, VD3 1A hydroxylase ${ }^{+}$macrophages (synthesize calcitriol), and phosphorylated SMAD2 in most cells [suggesting active transforming growth factor (TGF)- $\beta$ ], each corroborated by RNA sequencing.
Chemokines CCL18 and CCL13 are significantly upregulated, substantially explaining what cells are recruited to form the infiltrates. ALOX15 contents are increased, explaining the presence of CCL18 and CCL13. HPGD contents (15-PGDH, which metabolizes eicosanoids) are substantially decreased in EGPA, mainly in alveolar epithelium, although there was staining compatible with known basophil and Treg 15-PGDH expression. ${ }^{22}$ Decreased 15-PGDH suggests that eicosanoid signaling could be accentuated in EGPA.

Except for a study of CD83 and CD208, ${ }^{17}$ this is, to our knowledge, the first immunostaining study of lung tissue in EGPA. This is the first lung tissue transcriptome study in EGPA. Prior studies examined the routine histopathology of EGPA, showing abundant eosinophils, macrophages with giant cells, lymphocytes, plasma cells, and eosinophilic vasculitis in lung tissue. ${ }^{23-26}$ Bronchoalveolar lavage studies have shown significant EGPA-related increases in type 2-related cytokines, FOXP3 and $I L 10,{ }^{18}$ and ALOX15-related eicosanoids, ${ }^{27}$ supporting our findings of Tregs and other immunoregulatory features. Although a prior study suggested that eosinophils have FoxP3, ${ }^{28}$ all FoxP $^{+}$were found to be $\mathrm{CD} 3^{+} \mathrm{T}$ cells. Although $\mathrm{IgG} 4$ plasma cells have not been previously reported in the lungs in EGPA and they are reportedly absent in the upper respiratory tract ${ }^{7}$ of EGPA patients, modest numbers of IgG4 plasma cells have been demonstrated in nerve biopsies from EGPA patients. ${ }^{29}$ 
Table 2 RNA-Sequencing Results

\begin{tabular}{|c|c|c|c|c|}
\hline Gene name & Base mean & Log2 fold change & $\begin{array}{l}\text { RNA-sequencing } \\
\text { adjusted } P \text { value }\end{array}$ & Comments \\
\hline \multicolumn{5}{|c|}{ Genes significantly different } \\
\hline CCL18 & 45.7 & 6.13 & $5.8 \times 10^{-5}$ & Recruits Treg and Th2 via CCR8. \\
\hline CCL13 & 10.9 & 4.25 & 0.0022 & Recruits macrophages, eosinophils, and basophils. \\
\hline ALOX15 & 203 & 3.55 & 0.024 & $\begin{array}{l}\text { Arachidonate } 15 \text {-lipoxygenase. Its eicosanoid products } \\
\text { induce macrophages } C \mathrm{CL} 18, \mathrm{CCL} 13 \text {, and } \mathrm{CCL} 22 \text {. }\end{array}$ \\
\hline LTC4S & 49 & 4.35 & 0.0022 & $\begin{array}{l}\text { Leukotriene C4 synthase. Makes leukotriene C4 and } \\
\text { eoxin C } 4 \text {. }\end{array}$ \\
\hline \multicolumn{5}{|c|}{ Type 2 related } \\
\hline IL13 & 0.58 & 3.98 & & Type 2 cytokine. Significantly increased by RT-PCR. \\
\hline SIGLEC8 & 34.7 & 4.11 & $8.5 \times 10^{-5}$ & Receptor on mast cells and eosinophils. \\
\hline FOXP3 & 17.3 & 3.04 & 0.0015 & Tregs. Can be expressed in other cell types. \\
\hline IGHG4 & 26,478 & 10.88 & $1.7 \times 10^{-15}$ & IgG4 heavy chain. IgG4 is induced by IL- 10 . \\
\hline CYP27B1 & 12.8 & 3.44 & 0.004 & VD3 $1 \mathrm{~A}$ hydroxylase. Makes calcitriol (active vitamin D). \\
\hline INHBA & 40.0 & -2.10 & 0.013 & $\begin{array}{l}\text { Inhibin } \beta \text { A chain (activin A). Causes SMAD2 } \\
\text { phosphorylation. }\end{array}$ \\
\hline COL1A1 & 20,163 & 4.32 & $2.0 \times 10^{-7}$ & Major collagen gene. \\
\hline COL3A1 & 20,529 & 3.03 & 0.0021 & Major collagen gene. \\
\hline \multicolumn{5}{|c|}{ Genes not significantly different } \\
\hline IL10 & 9.3 & 3.02 & & $\begin{array}{l}\text { Regulatory cytokine. Increased in EGPA BAL in a prior } \\
\text { study. }\end{array}$ \\
\hline IL5 & 2.26 & -2.08 & & $\begin{array}{l}\text { Induces eosinophils. Increased in EGPA BAL in a prior } \\
\text { study. }\end{array}$ \\
\hline
\end{tabular}

15-PGDH, 15-hydroxyprostaglandin dehydrogenase $[\mathrm{NAD}(+)]$; BAL, bronchoalveolar lavage; LIGHT, tumor necrosis factor ligand superfamily member 14; Th2, type 2 helper T cell; TGF, transforming growth factor; Treg, regulatory T cell; VD3 1A hydroxylase, 25-hydroxyvitamin D-1 $\alpha$ hydroxylase, mitochondrial.

The $C C L 18$ and $C C L 13$ chemokine pattern is novel in EGPA and differs from the finding that CCL17 and CCL22, made by respiratory epithelium, are dominant in asthma. ${ }^{30}$ The presence of CCL18 also explains the apparent discrepancy between the increase in Tregs found in the present study and earlier work by two different groups demonstrating decreased peripheral blood Tregs in EGPA. ${ }^{12-17,31}$ Although Saito and Tsurikisawa and colleagues $^{12-17}$ concluded that Tregs have a protective effect in EGPA and are lost during active disease, these results suggest that, rather than being lost, Tregs are recruited to lung tissue, presumably by chemokine (C-C motif) ligand (CCL) 18, where they likely contribute to the immunoregulatory findings in EGPA. Other novel findings (to our knowledge for EGPA at any site) include expression of CYP27B1, HPGD, TNFSF14, ALOX15, HPGD, and their protein products, as well as TGF- $\beta$ activation (indicated by increased phosphorylated SMAD2), $\mathrm{IgG}^{+}$macrophage immune complexes, and increased numbers of Tregs and basophils.

Because EGPA is associated with an ILIO promotor haplotype with increased IL-10 secretion, ${ }^{10}$ the immunoregulatory features could be mechanistically relevant. Tissue-invasive filarial parasites induce an analogous IL-10 and IgG4 immune response that modulates disease by blocking parasite-specific IgE responses, avoiding elephantiasis, ${ }^{32}$ as well as impairing type 1 and type 2 helper T-cell immune pathways. ${ }^{33}$ We hypothesize that EGPA is a pathologic IL-10 and IgG4-related ${ }^{8}$ immune reaction analogous to an immune response to a tissue-invasive parasite, as previously proposed for eosinophilic esophagitis. ${ }^{34}$

We propose a mechanism that integrates our findings with prior functional studies (Figure 7). Arachidonate 15-lipoxygenase produces eicosanoids that, in alveolar 


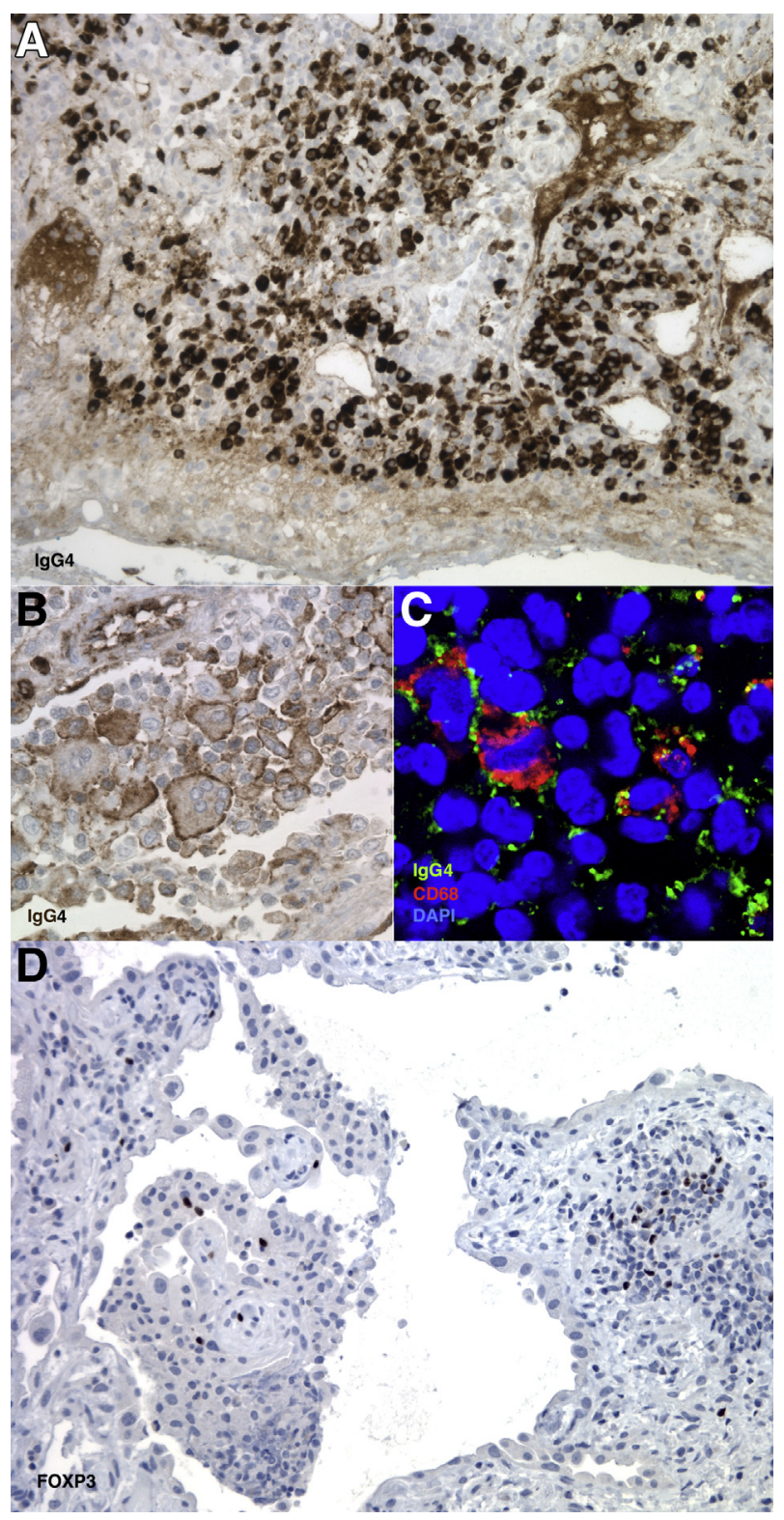

Figure 4 Eosinophilic granulomatosis with polyangiitis (EGPA) patients have abundant IgG4 plasma cells, granular extracellular and macrophage IgG4, and FoxP3 staining, suggesting regulatory $T$ cells. A: Lung biopsies from EGPA patients have, in some areas, abundant interstitial IgG4 plasma cells by IgG4 immunoperoxidase stain. Pleural surface is at bottom. B: Some alveolar macrophages and giant cells have predominantly cell membrane staining for IgG4. Eosinophils generally lack staining for IgG4. C: Confocal microscope image showing distinctly granular staining for IgG4 (green), resembling immune complexes. Focally, the IgG4 staining is at the surface of macrophages, with coarsely granular cytoplasmic CD68 immunostaining (red). D: EGPA biopsy. FoxP3 immunoperoxidase stain, with presumptive regulatory $T$ cells in alveolar macrophage aggregates (at left) and pleural interstitium (at right). Original magnification: $\times 88(\mathbf{A}) ; \times 125$ (B and D); $\times 500($ C).

macrophages in vitro, induce CCL18, CCL13, and CCL22. ${ }^{35}$ This effect is potentiated by decreased 15-PGDH, which metabolizes eicosanoids, effectively prolonging eicosanoid signaling. CCL18 recruits C-C chemokine receptor type 8-containing cells, particularly Tregs, which abundantly express this receptor, per the Human Protein Atlas. ${ }^{22}$ CCL18 also induces IL-10 and ALOX15. ${ }^{36}$ Tregs can produce IL-10 and TGF- $\beta$, induce basophil IL- $13,{ }^{3}$ and, in part via IL-10, induce macrophage CCL18. ${ }^{3}$ CCL18 also induces collagen synthesis, ${ }^{39}$ which induces further $C C L 18 .^{40}$ Although each of our lung biopsy cases are from early in the course of the disease before the EGPA diagnosis, the increased collagen mRNA is not surprising given the extensive fibrosis in advanced lesions. ${ }^{23}$ CCL13 and $C C L 26$ recruit eosinophils and basophils via CCR3.

IL-10 induces IgG4 plasma cells ${ }^{8}$ and macrophage TGF$\beta .^{41}$ IgG4 alveolar macrophage immune complexes induce macrophage IL-10. ${ }^{42}$ IgG4 blocking antibodies could suppress IgE-mediated macrophage activation and thus classic allergy. TGF- $\beta$ is also induced by LIGHT. ${ }^{43}$ TGF- $\beta$ induces Tregs, CYP27B1, collagen synthesis, and other regulatory effects. Although the concept of M2 macrophages ${ }^{41}$ is an oversimplification, EGPA lung has four main M2 stimuli: IL-13 (M2a), immune complexes (M2b), IL-10, and TGF- $\beta$ (M2c). Regulatory B cells, which are $\mathrm{IgG}^{+}$, could also be present. ${ }^{44,45}$ Calcitriol, the product of $C Y P 27 B 1 / \mathrm{VD} 31 \mathrm{~A}$ hydroxylase, has immunoregulatory features, ${ }^{46}$ but suppresses collagen synthesis and TGF- $\beta{ }^{47}$ These findings are summarized in Figure 7.

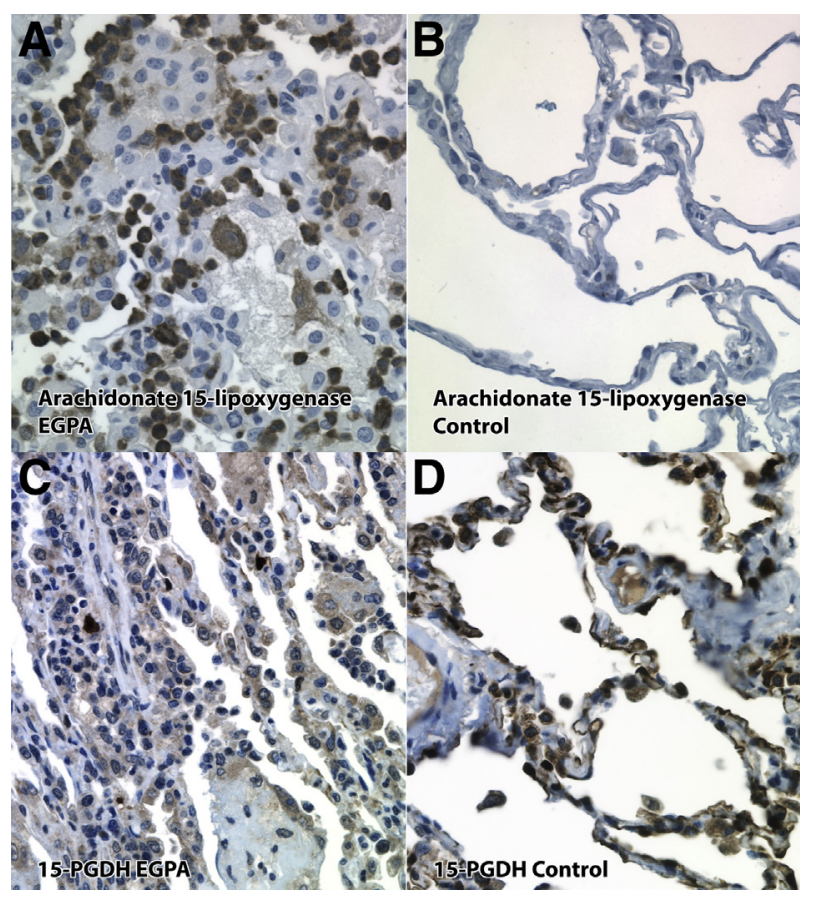

Figure 5 Eosinophilic granulomatosis with polyangiitis (EGPA) lung tissue immunostaining suggests increased expression of arachidonate 15lipoxygenase (ALOX15)-related eicosanoids. A: EGPA lung biopsy has extensive ALOX15 staining of all eosinophils and some alveolar macrophages. B: Control lungs have minimal ALOX15 staining. C: EGPA lung biopsy had 15-hydroxyprostaglandin dehydrogenase (15-PGDH) staining of a minority of lymphocytes and generally mononuclear cells with moderately abundant cytoplasm (presumed regulatory $T$ cells and basophils, respectively). D: Control lungs have extensive type 1 pneumocyte and alveolar macrophage $15-\mathrm{PGDH}$ immunostaining. Original magnification: $\times 150(\mathbf{A}$ and $\mathbf{B}) ; \times 120$ (C and D). 


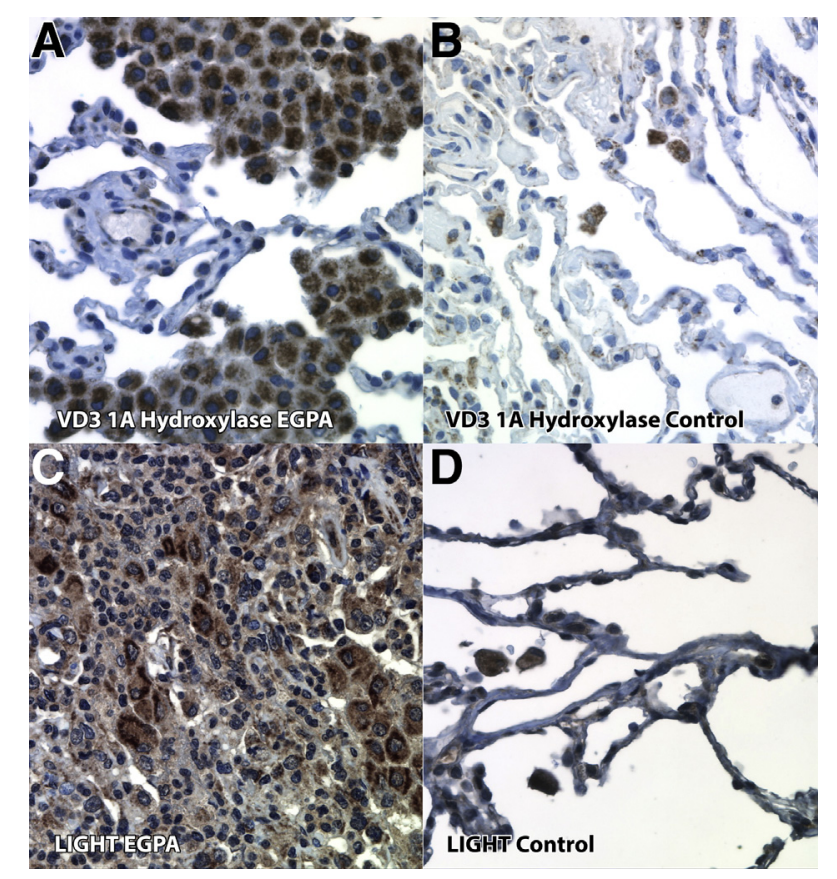

Figure 6 Eosinophilic granulomatosis with polyangiitis (EGPA) lung tissue immunostaining is increased relative to controls for 25 hydroxyvitamin D-1 $\alpha$ hydroxylase, mitochondrial (VD3 1A hydroxylase), and tumor necrosis factor superfamily member 14 (TNFSF14, also known as LIGHT), suggesting immunoregulatory and type 2 effects. A: EGPA biopsy showing extensive VD3 1A hydroxylase immunoperoxidase granular cytoplasmic staining, resembling mitochondria, in alveolar macrophages. B: Control lung showing similar VD3 1A hydroxylase staining of alveolar macrophages, but alveolar macrophages are sparse. C: EGPA lung biopsy showing cytoplasmic LIGHT immunostaining, mainly of alveolar macrophages. D: Control lung also has alveolar macrophage LIGHT immunostaining, but alveolar macrophages are sparse. Original magnification, $\times 135$ (A-D).

There remains a pressing need for improved EGPA treatment. To find appropriate treatment targets, we looked for self-promoting pathways (ie, positive feedback loops). A self-promoting EGPA pathway was previously found in a blood leukocyte study of eosinophils, IL-25, and type 2 helper T cells, which correctly predicted that eosinophils are mechanistically relevant in EGPA. ${ }^{11}$ Our data suggest that multiple potential self-promoting pathways could be activated in the lungs of EGPA patients, such as CCL18/CCR8/ Tregs, ${ }^{35,36,39,40,48}$ ALOX15, ${ }^{35,36}$ IL-10 and IgG4, ${ }^{8,41,49,50}$ IL-13, ${ }^{35,37,50}$ TGF- $\beta$ and Treg, ${ }^{41,43}$ CCL18, and collagen synthesis. ${ }^{39,40}$ These could be important in inducing or sustaining active inflammation and are thus potential treatment targets. We hypothesize that blocking CCL18 with pirfenidone $^{51}$ or blocking IL-13 plus IL-4 could be a useful treatment for EGPA. Other potential therapeutic targets include arachidonate 15-lipoxygenase-related eicosanoids, CCR8 (the CCL18 receptor), SIGLEC8, TNFSF14, and basophils.

Future studies could also explore the diagnostic value of abundant IgG4 plasma cells in distinguishing EGPA from eosinophilic pneumonia and eosinophilic pleuritis, which overlap substantially in both clinical manifestations and pathologic findings. Further studies are needed to examine the effects of IgG4 in EGPA, which could be pathogenic, protective, or both.

Limitations of this study are the number of biopsies available for study, all from patients with early EGPA. All lung biopsies for RNA studies were from females; sex-influenced RNAs could be misleading. This study did not compare EGPA with other eosinophil-rich or vasculitis-associated lung disorders; the EGPA specificity of this immunoregulatory immune response is unknown. Poorly preserved RNA from paraffinembedded tissue precluded assessment of low abundance RNAs; IL-5, IL-10, and CCL26 are particularly likely to be increased in EGPA and mechanistically relevant. However, the main novel findings (abundant IgG4 plasma cells and immunoregulatory features) were validated by immunostaining. Finally, this is an observational study. Functional studies are needed to assess the effects of these treatments, which will likely be complex and difficult to predict.

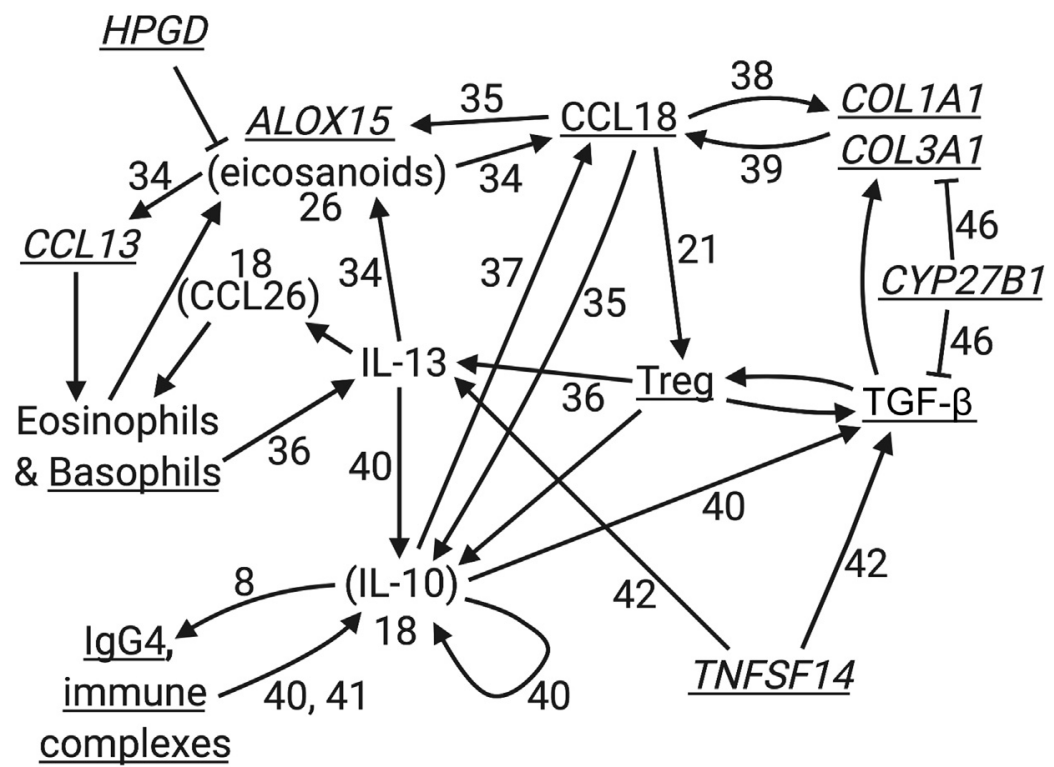

Figure 7 Hypothesized mechanism for eosinophilic granulomatosis with polyangiitis (EGPA), showing a combined type 2 and immunoregulatory immune response. Findings novel to this study (in the context of lung EGPA) are underlined. Findings based solely on prior work (that were not studied or not proved significant in our data) are in parentheses. Numbers by the arrows or findings in parentheses refer to references on which they are based. Despite the complexity, this is simplified; some pathways are left out for clarity. See Discussion for details. CCL, chemokine ( $\mathrm{C}-\mathrm{C}$ motif) ligand; TGF- $\beta$, transforming growth factor- $\beta$; Treg, regulatory $T$ cell. 
In summary, lung biopsies in EGPA have both type 2 and immunoregulatory features with Tregs and abundant IgG4. C-C motif chemokine 13 and C-C motif chemokine 18 are prominent chemokines. Eicosanoids are plausible intermediate signaling molecules. We propose a mechanism involving these to form a hybrid type 2 /immunoregulatory infiltrate resembling the immune response to a tissueinvasive parasite infection.

\section{Supplemental Data}

Supplemental material for this article can be found at http://doi.org/10.1016/j.ajpath.2020.03.005.

\section{References}

1. Wechsler ME, Akuthota P, Jayne D, Khoury P, Klion A, Langford CA, Merkel PA, Moosig F, Specks U, Cid MC, Luqmani R, Brown J, Mallett S, Philipson R, Yancey SW, Steinfeld J, Weller PF, Gleich GJ; EGPA Mepolizumab Study Team: Mepolizumab or placebo for eosinophilic granulomatosis with polyangiitis. N Engl J Med 2017, 376:1921-1932

2. Mohammad AJ, Hot A, Arndt F, Moosig F, Guerry MJ, Amudala N, Smith R, Sivasothy P, Guillevin L, Merkel PA, Jayne DR: Rituximab for the treatment of eosinophilic granulomatosis with polyangiitis (Churg-Strauss). Ann Rheum Dis 2016, 75:396-401

3. Thiel J, Troilo A, Salzer U, Schleyer T, Halmschlag K, Rizzi M, Frede N, Venhoff A, Voll RE, Venhoff N: Rituximab as induction therapy in eosinophilic granulomatosis with polyangiitis refractory to conventional immunosuppressive treatment: a 36-month follow-up analysis. J Allergy Clin Immunol Pract 2017, 5:1556-1563

4. Danieli MG, Cappelli M, Malcangi G, Logullo F, Salvi A, Danieli G: Long term effectiveness of intravenous immunoglobulin in ChurgStrauss syndrome. Ann Rheum Dis 2004, 63:1649-1654

5. Nathani N, Little MA, Kunst H, Wilson D, Thickett DR: ChurgStrauss syndrome and leukotriene antagonist use: a respiratory perspective. Thorax 2008, 63:883-888

6. Bibby S, Healy B, Steele R, Kumareswaran K, Nelson H, Beasley R: Association between leukotriene receptor antagonist therapy and Churg-Strauss syndrome: an analysis of the FDA AERS database. Thorax 2010, 65:132-138

7. Vaglio A, Strehl JD, Manger B, Maritati F, Alberici F, Beyer C, Rech J, Sinico RA, Bonatti F, Battistelli L, Distler JH, Schett G, Zwerina J: IgG4 immune response in Churg-Strauss syndrome. Ann Rheum Dis 2012, 71:390-393

8. Jeannin P, Lecoanet S, Delneste Y, Gauchat JF, Bonnefoy JY: IgE versus IgG4 production can be differentially regulated by IL-10. J Immunol 1998, 160:3555-3561

9. Vaglio A, Martorana D, Maggiore U, Grasselli C, Zanetti A, Pesci A, Garini G, Manganelli P, Bottero P, Tumiati B, Sinico RA, Savi M, Buzio C, Neri TM; Secondary and Primary Vasculitis Study Group: HLA-DRB4 as a genetic risk factor for Churg-Strauss syndrome. Arthritis Rheum 2007, 56:3159-3166

10. Wieczorek S, Hellmich B, Arning L, Moosig F, Lamprecht P, Gross WL, Epplen JT: Functionally relevant variations of the interleukin-10 gene associated with antineutrophil cytoplasmic antibody-negative Churg-Strauss syndrome, but not with Wegener's granulomatosis. Arthritis Rheum 2008, 58:1839-1848

11. Terrier B, Bieche I, Maisonobe T, Laurendeau I, Rosenzwajg M, Kahn JE, Diemert MC, Musset L, Vidaud M, Sene D, CostedoatChalumeau N, Le Thi-Huong D, Amoura Z, Klatzmann D, Cacoub P, Saadoun D: Interleukin-25: a cytokine linking eosinophils and adaptive immunity in Churg-Strauss syndrome. Blood 2010, 116: $4523-4531$

12. Saito H, Tsurikisawa N, Tsuburai T, Akiyama K: Involvement of regulatory T cells in the pathogenesis of Churg-Strauss syndrome. Int Arch Allergy Immunol 2008, 146 Suppl 1:73-76

13. Tsurikisawa N, Saito H, Tsuburai T, Oshikata C, Ono E, Mitomi H, Akiyama K: Differences in regulatory T cells between Churg-Strauss syndrome and chronic eosinophilic pneumonia with asthma. J Allergy Clin Immunol 2008, 122:610-616

14. Saito H, Tsurikisawa N, Tsuburai T, Oshikata C, Akiyama K: Cytokine production profile of $\mathrm{CD} 4+\mathrm{T}$ cells from patients with active Churg-Strauss syndrome tends toward Th17. Int Arch Allergy Immunol 2009, 149 Suppl 1:61-65

15. Saito H, Tsurikisawa N, Tsuburai T, Oshikata C, Akiyama K: The proportion of regulatory $\mathrm{T}$ cells in the peripheral blood reflects the relapse or remission status of patients with Churg-Strauss syndrome. Int Arch Allergy Immunol 2011, 155 Suppl 1:46-52

16. Tsurikisawa N, Saito H, Oshikata C, Tsuburai T, Akiyama K: Decreases in the numbers of peripheral blood regulatory $\mathrm{T}$ cells, and increases in the levels of memory and activated B cells, in patients with active eosinophilic granulomatosis and polyangiitis. J Clin Immunol 2013, 33:965-976

17. Tsurikisawa N, Saito H, Oshikata C, Tsuburai T, Ishiyama M, Mitomi H, Akiyama K: An increase of CD83+ dendritic cells ex vivo correlates with increased regulatory $\mathrm{T}$ cells in patients with active eosinophilic granulomatosis and polyangiitis. BMC Immunol 2014, $15: 32$

18. Jakiela B, Szczeklik W, Plutecka H, Sokolowska B, Mastalerz L, Sanak M, Bazan-Socha S, Szczeklik A, Musial J: Increased production of IL-5 and dominant Th2-type response in airways of Churg-Strauss syndrome patients. Rheumatology 2012, 51: $1887-1893$

19. Masi AT, Hunder GG, Lie JT, Michel BA, Bloch DA, Arend WP, Calabrese LH, Edworthy SM, Fauci AS, Leavitt RY, Lightfoot RW, McShane DJ, Mills JA, Stevens MB, Wallace SL, Zvaifler NJ: The American College of Rheumatology 1990 criteria for the classification of Churg-Strauss syndrome (allergic granulomatosis and angiitis). Arthritis Rheum 1990, 33:1094-1100

20. Peterson KA, Yoshigi M, Hazel MW, Delker DA, Lin E, Krishnamurthy C, Consiglio N, Robson J, Yandell M, Clayton F: RNA sequencing confirms similarities between PPI-responsive oesophageal eosinophilia and eosinophilic oesophagitis. Aliment Pharmacol Ther 2018, 48:219-225

21. Flygare S, Simmon K, Miller C, Qiao Y, Kennedy B, Di Sera T, Graf EH, Tardif KD, Kapusta A, Rynearson S, Stockmann C, Queen K, Tong S, Voelkerding KV, Blaschke A, Byington CL, Jain S, Pavia A, Ampofo K, Eilbeck K, Marth G, Yandell M, Schlaberg R: Taxonomer: an interactive metagenomics analysis portal for universal pathogen detection and host mRNA expression profiling. Genome Biol 2016, 17:111

22. Uhlen M, Fagerberg L, Hallstrom BM, Lindskog C, Oksvold P, Mardinoglu A, et al: Proteomics. tissue-based map of the human proteome. Science 2015, 347:1260419

23. Churg J, Strauss L: Allergic granulomatosis, allergic angiitis, and periarteritis nodosa. Am J Pathol 1951, 27:277-301

24. Churg A, Brallas M, Cronin SR, Churg J: Formes frustes of ChurgStrauss syndrome. Chest 1995, 108:320-323

25. Katzenstein AL: Diagnostic features and differential diagnosis of Churg-Strauss syndrome in the lung: a review. Am J Clin Pathol 2000, 114:767-772

26. Churg A: Recent advances in the diagnosis of Churg-Strauss syndrome. Mod Pathol 2001, 14:1284-1293

27. Szczeklik W, Sanak M, Mastalerz L, Sokolowska BM, Gielicz A, Soja J, Kumik J, Musial J, Szczeklik A: 12-Hydroxy-eicosatetraenoic acid (12-HETE): a biomarker of Churg-Strauss syndrome. Clin Exp Allergy 2012, 42:513-522 
28. Lingblom $\mathrm{C}$, Wallander $\mathrm{J}$, Ingelsten $\mathrm{M}$, Bergquist $\mathrm{H}$, Bove $\mathrm{M}$, Saalman R, Welin A, Wenneras C: Eosinophils from eosinophilic oesophagitis patients have $\mathrm{T}$ cell suppressive capacity and express FOXP3. Clin Exp Immunol 2017, 187:455-465

29. Ohyama K, Koike H, Takahashi M, Kawagashira Y, Iijima M, Watanabe H, Sobue G: Immunoglobulin G4-related pathologic features in inflammatory neuropathies. Neurology 2015, 85:1400-1407

30. Panina-Bordignon P, Papi A, Mariani M, Di Lucia P, Casoni G, Bellettato C, Buonsanti C, Miotto D, Mapp C, Villa A, Arrigoni G, Fabbri LM, Sinigaglia F: The C-C chemokine receptors CCR4 and CCR8 identify airway $\mathrm{T}$ cells of allergen-challenged atopic asthmatics. J Clin Invest 2001, 107:1357-1364

31. Jakiela B, Sanak M, Szczeklik W, Sokolowska B, Plutecka H, Mastalerz L, Musial J, Szczeklik A: Both Th2 and Th17 responses are involved in the pathogenesis of Churg-Strauss syndrome. Clin Exp Rheumatol 2011, 29:S23-S34

32. Hussain R, Poindexter RW, Ottesen EA: Control of allergic reactivity in human filariasis: predominant localization of blocking antibody to the IgG4 subclass. J Immunol 1992, 148:2731-2737

33. Babu S, Blauvelt CP, Kumaraswami V, Nutman TB: Regulatory networks induced by live parasites impair both Th1 and Th2 pathways in patent lymphatic filariasis: implications for parasite persistence. J Immunol 2006, 176:3248-3256

34. Clayton F, Fang JC, Gleich GJ, Lucendo AJ, Olalla JM, Vinson LA, Lowichik A, Chen X, Emerson L, Cox K, O'Gorman MA, Peterson KA: Eosinophilic esophagitis in adults is associated with IgG4 and not mediated by IgE. Gastroenterology 2014, 147:602-609

35. Abrial C, Grassin-Delyle S, Salvator H, Brollo M, Naline E, Devillier P: 15-Lipoxygenases regulate the production of chemokines in human lung macrophages. Br J Pharmacol 2015, 172:4319-4330

36. Schraufstatter IU, Zhao M, Khaldoyanidi SK, Discipio RG: The chemokine CCL18 causes maturation of cultured monocytes to macrophages in the M2 spectrum. Immunology 2012, 135:287-298

37. Sharma M, Das M, Stephenvictor E, Galeotti C, Karnam A, Maddur MS, Bruneval P, Kaveri SV, Bayry J: Regulatory T cells induce activation rather than suppression of human basophils. Sci Immunol 2018, 3:eaan0829

38. Tiemessen MM, Jagger AL, Evans HG, van Herwijnen MJ, John S, Taams LS: CD4+CD25+Foxp3+ regulatory T cells induce alternative activation of human monocytes/macrophages. Proc Natl Acad Sci U S A 2007, 104:19446-19451

39. Luzina IG, Tsymbalyuk N, Choi J, Hasday JD, Atamas SP: CCL18stimulated upregulation of collagen production in lung fibroblasts requires Sp1 signaling and basal Smad3 activity. J Cell Physiol 2006, 206:221-228
40. Prasse A, Pechkovsky DV, Toews GB, Jungraithmayr W, Kollert F, Goldmann T, Vollmer E, Muller-Quernheim J, Zissel G: A vicious circle of alveolar macrophages and fibroblasts perpetuates pulmonary fibrosis via CCL18. Am J Respir Crit Care Med 2006, 173:781-792

41. Wang LX, Zhang SX, Wu HJ, Rong XL, Guo J: M2b macrophage polarization and its roles in diseases. J Leukoc Biol 2019, 106: 345-358

42. Bianchini R, Roth-Walter F, Ohradanova-Repic A, Flicker S, Hufnagl K, Fischer MB, Stockinger H, Jensen-Jarolim E: IgG4 drives M2a macrophages to a regulatory M2b-like phenotype: potential implication in immune tolerance. Allergy 2019, 74:483-494

43. Doherty TA, Soroosh P, Khorram N, Fukuyama S, Rosenthal P, Cho JY, Norris PS, Choi H, Scheu S, Pfeffer K, Zuraw BL, Ware CF, Broide DH, Croft M: The tumor necrosis factor family member LIGHT is a target for asthmatic airway remodeling. Nat Med 2011, $17: 596-603$

44. van de Veen W, Stanic B, Wirz OF, Jansen K, Globinska A, Akdis M: Role of regulatory B cells in immune tolerance to allergens and beyond. J Allergy Clin Immunol 2016, 138:654-665

45. van de Veen W, Stanic B, Yaman G, Wawrzyniak M, Sollner S, Akdis DG, Ruckert B, Akdis CA, Akdis M: IgG4 production is confined to human IL-10-producing regulatory B cells that suppress antigen-specific immune responses. J Allergy Clin Immunol 2013, 131:1204-1212

46. Vanherwegen AS, Gysemans C, Mathieu C: Regulation of immune function by vitamin D and its use in diseases of immunity. Endocrinol Metab Clin North Am 2017, 46:1061-1094

47. Li SR, Tan ZX, Chen YH, Hu B, Zhang C, Wang H, Zhao H, Xu DX: Vitamin D deficiency exacerbates bleomycin-induced pulmonary fibrosis partially through aggravating TGF-beta/Smad2/3-mediated epithelial-mesenchymal transition. Respir Res 2019, 20:266

48. Barsheshet Y, Wildbaum G, Levy E, Vitenshtein A, Akinseye C, Griggs J, Lira SA, Karin N: CCR8(+)FOXp3(+) Treg cells as master drivers of immune regulation. Proc Natl Acad Sci U S A 2017, 114 6086-6091

49. Edwards JP, Zhang X, Frauwirth KA, Mosser DM: Biochemical and functional characterization of three activated macrophage populations. J Leukoc Biol 2006, 80:1298-1307

50. Swisher JF, Haddad DA, McGrath AG, Boekhoudt GH, Feldman GM: IgG4 can induce an M2-like phenotype in human monocyte-derived macrophages through FcgammaRI. mAbs 2014, 6 : $1377-1384$

51. Saito Y, Azuma A, Matsuda K, Kamio K, Abe S, Gemma A: Pirfenidone exerts a suppressive effect on CCL18 expression in U937derived macrophages partly by inhibiting STAT6 phosphorylation. Immunopharmacol Immunotoxicol 2016, 38:1-8 